\title{
Legal English. The UN Convention on Genocide as a Domain-Specific Text
}

\author{
Seda Gasparyan, Lilit Kharatyan \\ Yerevan State University
}

\begin{abstract}
The question of the interaction of language and law is one of the main issues occupying the minds of both the linguists and jurists of our time. The study of the intersection of these scientific fields acquires even more importance nowadays as expansion of economic and cultural cooperation between countries and within countries requires legal regulation, qualified assistance of lawyers and their participation in negotiations, business meetings and in the preparation of documentation. Accordingly, linguistic and translation activities in the sphere of legal relations turn out to be of special significance. Like other functional styles of speech, which are independent systems, the style of official documents has certain communicative goals as well as its own consistent patterns and language characteristics common to the given style. The latter are the subject of the present article.
\end{abstract}

Key words: legal linguistics, a domain-specific language, legal English, the Genocide Convention as a legal text, language characteristics, layout features.

\section{Introduction}

It has already been established that the branch of science dealing with issues of language and law can be described by the metalinguistic notion of legal linguistics. In the middle of the last century, this term occurred to mean a set of methods and research results connected with the relationship of language and legal norms, and meet the requirements of modern linguistics. The understanding of legal linguistics has significantly expanded due to the developmental changes modern linguistics has undergone, particularly 
stimulation of interdisciplinary research the productivity and reliability of which is already beyond doubt.

Over the last decades a number of scholars have tried to define what "legal language" is, however most of their studies have not proved to be systematic, and the definitions offered for the language used in legal processes did not transfer all the properties and functions obtained by this style. Some scholars discuss only the written variety of legal language defining it as legal writing with its three subtypes: academic legal writing, juridical writing and legislative writing (Bhatia 2010:46). There can be no doubt that the presented distinction is quite acceptable. However, obvious is the fact that this style of language is not confined to its written form only.

The Jewish linguist Kurzon, going further and offering two terms for specific legal procedures, argues that language of the law is "the language or the style used in documents laying down the law", whereas legal language refers to the language that is "used to talk about the law". The latter can appear both in written (judgements, textbooks, etc.) and oral forms (formal speech, witness questioning, etc.). The oral subtype of legal language can also be referred to as law talk (Kurzon 1989:284).

The present investigation aims at singling out the main features of English legal style with special reference to the English text of the UN Convention on Genocide as a domain-specific text and drawing some parallels between the original text and its Armenian translation.

\section{Legal English as a Domain-Specific Language}

According to Galperin legal language is a substyle of official style, and like other styles of language, it has a definite communicative aim and its own system of interrelated language and stylistic means. The basic feature of presenting legal style is accuracy, which excludes the possibility of any kind of uncertainty and ambiguity; a narrow range of speech tools used in the text; language standard which can be accounted for by the desire to express thoughts in a uniform way and use this ready-made language formulaic-cliches; high degree of repeatability (frequency of use) of individual sections of the texts of 
documents. These features are reflected in the structure of the text when drawing up official papers and legal documents: formation of composition, arranging different parts of the text, separating paragraphs, font, etc. (Galperin 1981:68).

The most important qualities of legal documents are completeness and logical follow-up of information, accuracy, and conciseness of formulations. Neutral tone of narration is a norm for official style. Therefore, in a piece of legal speech an emotionally expressive coloring of language means (nouns and adjectives with suffixes of subjective evaluation, evaluative adjectives, etc.) occurs rarely. The use of colloquial, vernacular, dialectal words, phraseological units, etc. in legal speech is unacceptable. In fact, the literature on legal English suggests that in a number of ways it differs from ordinary speech, namely - the abundant use of professional terminology, impersonal constructions, long and complex sentences with passive constructions and multiple negations, etc. (Trosborg 1995; Groot 1998; Gibbons 2003, etc.). From a lexical point of view it is characterized by wordiness and nominalization, the use of formal vocabulary, foreignisms, etc.

Among other things, legal English is distinguished by a number of important features due to which it is characterized as unique and intricate in its nature. Investigations have long established precision and clarity, as well as the use of lexical elements, terms included, in a strictly defined sense as one of the basic characteristics of this variety of English. The use of grammatical constructions excluding ambiguity provides simplicity and reliability to legal English, for implementation of inaccurate language may result in ambiguity of sense and hamper the process of understanding in the sphere of legislative communication. Another quality of legal English is the neutrality of language which excludes the possibility of either exerting emotional pressure or revealing one's legal assessment. The occurrence of unjustified innovations is not allowed in legal English as they will violate its systemic nature meant to preserve the system of concepts relevant for the legal sphere (Berman and Greiner 1972; Tiersma 1999; Sahakyan 2012, etc.).

Investigations show that the history of English is the milestone of legal English and the terminology of the domain. In fact, it is a story of Anglo-Saxon 
mercenaries, Latin-speaking missionaries, Scandinavian raiders, Norman invaders who all left their mark not only on England but also on the language of its law. Therefore, it is not by chance at all that modern legal English owes, to a great extent, to Latin and French. Throughout different periods of the development of the English language certain changes have taken place in either their form or semantic structure, whereas some still retain their original characteristic features. For example, terms like inflict - Latin inflictus (15c.), conspiracy - Latin conspirationem, Old French conspiracie (mid. 14c), incitement - Latin incitamentum (early 15c.), tribunal - directly from Latin tribunal (early 15c.), treatyLatin tractatus, Old French traitié, Anglo-French treté (late14c.), suppress - Latin suppressus (late 14c.), deposit - Latin depositum, from deponere (1620s), etc. are still used daily in legal English. Many of them, however, are now practically unknown outside legal circles, sometimes because they are used in their etymological versions.

Our observations in the text of the Convention on Genocide which is a document of paramount international importance, reveal that the French expression procès-verbal in Article 14 of the Convention has been preserved without any change or interpretation, whereas in the Armenian version the official term upáuíuqpnıpjnı\& comes to present an equivalent translation.

Due to the vast amount of borrowings, legal English has acquired a number of characteristics. Besides the terms borrowed from French, modern legal English has preserved some features of legal French, such as inversion of the word order of an attributive construction which is a widespread phenomenon in legal language. However, in the text of the Convention it is confined to a single case only: Secretary General - Q./huulnp pupunnıqup. One can easily notice that the Armenian version of the Convention has confided on the classic use of syntax.

Not only did the loans replenish and enrich the English legal terminology but also make it unique and intricate. Some of the factors that make the English legal terminology unique and complex include the use of synonyms referring to the same legal concept. 
The text of the Convention is not an exception. Thus, for example, provision, paragraph, article - hnnyul; confirm, ratify - huuunuut t; etc. Albeit these words are not exact synonyms for, largely speaking, there are no exact synonyms at all, they are very close to each other in meaning and with only a few semantic and stylistic differences. The legal use of the term article means separate clause or item in an agreement or a contract (OALD 2005:72) ${ }^{1}$, while paragraph is a section of a piece of writing usually consisting of several sentences dealing with a single subject (OALD 2005:1099). Paragraphing is a typological device for arranging a legislative text. It involves dividing a sentence into grammatical units and arranging them as separate blocks of text. Provision defines a condition or an arrangement in a legal document (OALD 2005:1215). Investigation of semantic relations between confirm and ratify reveals that the definition of the word confirm in the dictionary is rather wide: to make a position, agreement, etc. more definite or official; to establish sth. firmly (OALD 2005:318), while ratify is a legal term proper meaning to make an agreement officially valid by voting for or signing it (OALD 2005:1251). Thus, the given units, as far as legal English is concerned, are very closely semantically related. This possibility of using synonymous language units can, as mentioned above, be accounted for by the fact that the same concept can be expressed by more than one language form, not infrequently by variants in the form of own vs foreign synonymous forms. Most common types of synonym pairs (doublets or binomials) having two lexical units, appear in the text of the Convention, too. The use of the noun-binomial application or fulfillment 4hpunnuर quu Guunupnzu is a case in point.

We should hasten to add however that the use of antonym pairs is not alien to legal English either. The inclusive effect and the ability of antonymous pairs to refrain from ambiguity and misunderstanding are obvious in the Convention

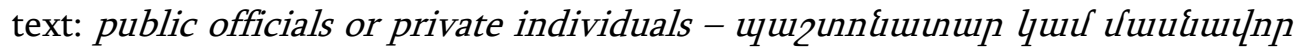
ukdhip; in whole or in part - Lphy quU Uuukulh; in time of peace or in time

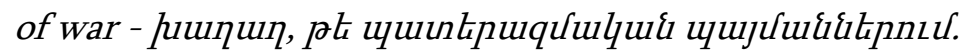

The analysis of the text shows that the use of other formal words, which are considered archaic and rarely used in daily conversation occurs very often. 
Being used less frequently than other terms, they appear rather obscure in the course of time. For example, in the text of the Convention we come across archaisms like hereinafter (Ilippnhh2Jul), thereof (nnh), thereafter (-). Notable is the fact that in the Armenian translation the archaism thereafter of the original has been completely ignored. As dictionaries testify (Kouyoumdjian 1981:1272), it could have been represented in the translation with the help of the following possible units: upuing htunn, ujp wuhhg h ylip, htunliupup.

While some of the English concepts are archaic and bookish, some of their Armenian equivalents (Ekpnhh2jul, nph, etc.) are more or less frequently used in casual communication. In the Armenian text of the Convention the opposite process can also be observed. Elements of ordinay use in English are translated by archaic units in Armenian (present - unujk, to depose - hukdikt f uquh, etc.). However it should be noted that although these forms pursue the goal of making the idea detailed, comprehensive and emphasized, they often complicate the cognitive process and become unnecessary additions. Despite this, the tendency retains their relevant use.

Along with these terms lawyers use less formal words, phrases and even idioms or, in other words, jargonisms which seemingly make the communication easy, though, in fact, they turn out to be rather difficult for a layman to understand. D. Mellinkoff defines this specialized lexis as argot which, like slang words, are produced by lawyers themselves for convenience. He believes that terms and terminological expressions proper intensify formality in legal English and impart specific semantic preciseness to speech (Mellinkoff 1963:17):

Another interesting characteristic feature of legal English is the use of the socalled common words with uncommon meanings. The use of such language elements in their primary dictionary meanings is generally aimed at avoiding possible misunderstandings or ambiguity, or inappropriate emotionality. The use of the same word with the same sound structure in a legal text with a meaning different from its legal meaning shows the potential of the word to express different concepts. If, for example, the word provision is used in financial sphere to mean an amount set aside out of profits in the accounts of an organization for a known liability, especially a bad debt or the diminution in value of an asset (FDF)', or in a 
religious text it means an appointment to a benefice, especially directly by the Pope rather than the patron, and originally it became vacant(FDF), in the context of the Convention its terminological meaning is actualized as a condition or requirement in a legal document (OALD 2005:1215) (privision - npnujp).

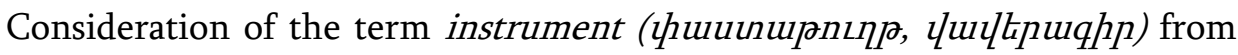
the same viewpoint shows that its basic meaning is a tool or device used for a particular task especially for delicate or scientific work (surgical, optical, precision, etc) (OALD 2005:806). In the sphere of arts this term usually refers to a device designed to enable a person to make musical sounds (FDF). However, in a legal context it acquires an additional meaning and indicates a formal or legal document (FDF).

The study of the language units resolution, law, ratification, provision, jurisdiction, legislation, punishment, crime, aim, humanity, co-operation, peace, war, conspiracy, prevention, suppression, accession, revision, etc. in the context of the Genocide Convention comes to show a very high degree of terminological generalization and abstraction. In fact, the use of such nomenclature units in legal documents aims at emphasizing the basic concepts in the context. On the other hand, their presence in legal documents and in the text of the Convention in particular mark the tendency of nominalization which is a preferred use in similar documents. Albeit they make sentences much longer and tend to disjoint their parts, they introduce definite and rather precise meanings into legal texts, hence the impossibility of their substitution for verbs. Thus, for example, give effect to the provision of the present Convention; consider appropriate for the prevention and suppression of acts; the declaration made by the General Assembly of the United Nations in its resolution; direct and public incitement to commit genocide; relating to the interpretation, application or fulfillment of the present Convention; etc.

Considerations of the morphologically relevant peculiar features of legal English bring out the use of specific grammatical constructions. Among them Passive constructions are the most intensively used ones and are aimed to secure the desirable effect of impersonality and lay the emphasis on the action rather than the actor. In the text of the Convention obvious is the realization of 
the intention to preserve the principle of objectivity as far as the presented material is concerned, and emphasize the importance of implementing the main action. E.g.:

- The present Convention shall be ratified, and the instruments of ratification shall be deposited with the Secretary-General of the United Nations.

- Genocide and the other acts enumerated in article III shall not be considered as political crimes for the purpose of extradition.

- The present Convention may be acceded to on behalf of any Member of the United Nations.

Even in rare cases when the doer of the action is mentioned, the preference is given to the action. The examples adduced below illustrate the case in point:

- Persons charged with genocide or any of the other acts enumerated in article III shall be tried by a competent tribunal of the State in the territory of which the act was committed.

- An invitation to sign has been addressed by the General Assembly.

- $A$ request for the revision of the present Convention may be made at any time by any Contracting Party.

High frequency of use of modal verbs, shall and may in particular, is also typical of legal texts. Modal verbs mark the action as possible, probable, impossible, obligatory, and advisable. They are used in such ethical concepts as obligation and permissibility. In the English text of the Convention the modal verb may expresses permission and authorization which in the Armenian variant is conveyed by qupnn 5 or ulunp 5 ”.

- Any Contracting Party may call upon the competent organs of the United Nations.

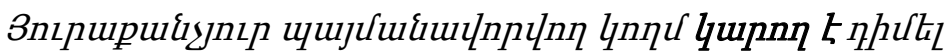




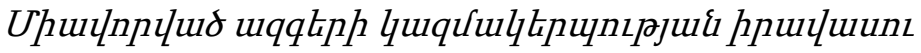 uupuhintiphi:}

The stylistic use of the modal verb shall in legal language is also remarkable. Its basic function in legal documents is the statement of laws, regulations, commands, determination. According to Webster's New World Dictionary, shall is used in formal style to express an explicit obligation. In Armenian, this modality is expressed mainly through Present Simple:

- Persons charged with genocide ... shall be tried by a competent tribunal of the State.

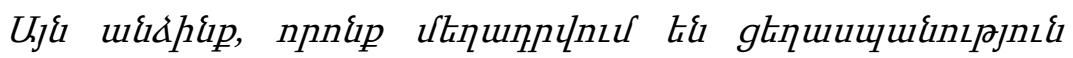

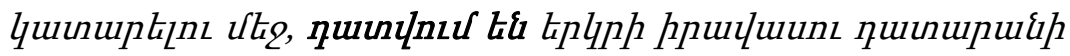
liniuhg:

- Acts enumerated in article III shall not be considered as political crimes.

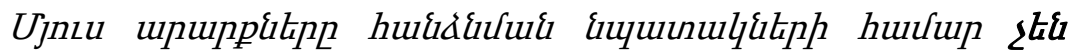

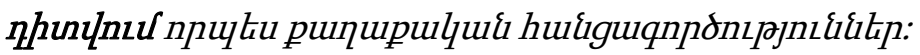

The study of the Armenian translation reveals that in terms of content shall is more comprehensive, as it does not show order, obligation, commitment, threat, warning, and promise. Being used in other semantic contents, it excludes severity and shows permission, probability of implementation of some activity, conditioned by a series of circumstances, thus coming close to the modal verb may.

Legal documents are also specific from the point of view of their graphological layout. Crystal and Davy point out that legal documents were traditionally made as solid blocks of script whose long lines were from margin to margin and there were no patterns of spacing or indentation to indicate the limits of the paragraphs or the relation between them. It was common for drafters to compose an entire document in the form of one single sentence (Crystal and Davy 1999:194). However nowadays, in legal writing much importance is attached to the structure and composition of the text in order to maintain the clarity and precision of the 
message conveyed. Thus, it is not by chance that Farghal and Shunnaq write in this connection: "Layout refers to the sketch or plan of the texts' physical appearance. This relates to paragraphing, indentation and graphitic choices, Viz. capitalizing, italicizing, underlining and bold-typing" (Farghal \& Shunnaq 1999: 205).

If we try to consider the text of the Convention on Genocide from the mentioned points of view an interesting picture will be revealed. The text starts with a short preamble representing the background of the document, the need for its constitution and the objective. It should be noted that this is a structural feature characteristic of conventions, declarations and other agreements and treaties of universal scale in general. The main points of the Convention, i.e. the Articles, come immediately after the Preamble. The Articles are divided into paragraphs enumerated with Roman numbers each of which represents one complete idea, a so-called provision. Some of the Articles consist of more than one paragraph or include multilevel lists as needed. It can be observed that the specific layout of the text of the Convention on Genocide is imposed by the message conveyed in the document.

It is beyond suspicion that dealing with legal language needs special care as most of our everyday common activities are carried out within a legal context. Therefore there is a tendency to make legal texts more cohesive and coherent through opting for a more consistent layout. Accordingly legal drafters start to give much attention to the graphitic and graphological devices such as italicizing, bolding and so on (Crystal and Davy 1986:189). However, the text of the Convention is not very rich in similar cases. Our observations of both the English and the Armenian texts of the Convention reveal the use of italicizing to highlight the number of the Articles in the English text whereas in the Armenian version text-bolding is employed for the same purpose.

A case of italicization occurs in Article XIII of the English text where the use of the Latin expression process-verbal is italicized to underline its metalinguistic value. The presence of the asterisk $\left(^{*}\right)$ on the mentioned expression refers to the footnote providing the explanation of its meaning. This, however, does not appear in the translated version of the text as the Armenian translator has chosen to use the Armenian equivalent of the Latinism in the target language. 
Among the characteristic features of legal documents capitalization of words and particularly of initial letters can also be mentioned. This is usually acomplished by either typing the chosen words in a larger font size than the remainder of the text or writing it all in capitals. Our study of the Convention text both in English and Armenian marks rather a large amount of cases of capitalizing. Thus, e.g.:

- CONVENTION ON THE PREVENTION AND PUNISHMENT OF THE CRIME OF GENOCIDE

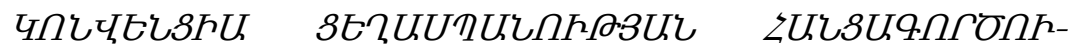

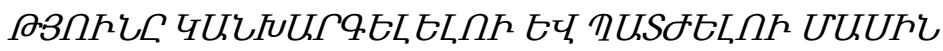

Capitalization can also be observed in the initial part of the Preamble of the English text to emphasize the paramount importance of introducing the Document, thus distinguishing the even more significant sections of speech from the rest of the sentence. In this case the initial letters of capitalized words appear in even a larger size to mark the beginning of the sentence:

- HAVING CONSIDERED the declaration ...

- RECOGNIZING that at all periods ...

- BEING CONVINCED that ...

However, the Preamble of the Armenian version refrains from using capital letters, and this fact can be accounted for by the differences in the graphological traditions of English and Armenian.

- huzy/h unitilnul, np ...

- pinnziliznц, np uuunúnupjuí pninp ...

- huuरnquud Lhitilnul, np ...

Instances of capitalization can also be observed in the presentation of organizations and institutions (United Nations - Uhuцnnцuı uqqkph quq-

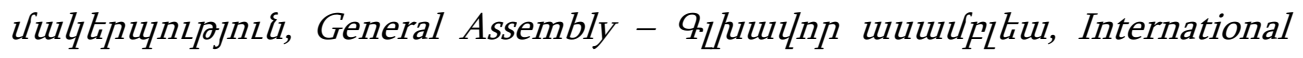
Court of Justice - Uhquqqujhi quinupui), official positions (Secretary Ge-

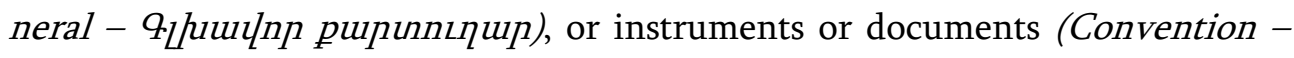

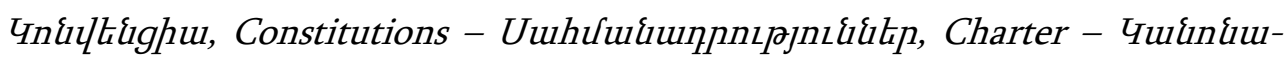


прпцдjnц\{1). In all these cases both the creators of the original and the target texts are guided by the working graphological rules of the languages in question.

The presence/absence of punctuation marks is another characteristic feature of legal texts. English legal texts are not infrequently characterized by absence of punctuation to avoid forgery, for punctuation marks can be as easily erased from documents as they can be put in, thus sometimes introducing grave changes in the legal meanings intended to be conveyed to the readers. Thinness of punctuation and presence of long uninterrupted sentences effectively provide a high level of formality in the language of English legal documents. Notwithstanding this fact there are, however, some ways they can be used where they are needed. If, for example, there is the necessity of emphasizing either the beginning or end of a phrase, clause or sentence, or a piece of new and highly important or contrastive information of essential value, commas, semi-colons or full stops may be used. In the English text of the Convention different cases of such applications of punctuation appear:

- HEREBY AGREE AS HEREINAFTER PROVIDED:

- The following acts shall be punishable:

(a) Genocide; (b) Conspiracy to commit genocide;

(c) Direct and public incitement to commit genocide;

- a national, ethnical, racial or religious group

Due to the complicated nature of the Armenian syntax and word order the need for precise punctuation is inevitable, Consequently, the Armenian version of the Convention makes use of punctuation marks not only in the cases mentioned above, but also in nearly all the sentences of the Articles.

It is quite obvious that much care and interest are given to legal texts through the use of layout features for the sake of revealing structure, content, and logical progression as a guide to facilitate interpretation. Therefore, layout features need to be respected in any type of legal drafting. 


\section{Conclusion}

Thus, the functioning of the above-mentioned features creates a specific stylistic system regulated by certain rules in legal English whereas their application outside the formal and official spheres may lead to stylistic errors and sometimes to unjustified complication of texts.

The examples adduced above come to prove that legal texts are quite distinct from other writings, and this is first and foremost accounted for by the textual convention of the profession. Despite the fact that legal language is quite limited, many legal texts come in a variety of genres, and each of them tends to have its stereotypical format and fixed structure. Hence, legal translation is considered to be a very complicated process consisting of various comprehensive steps.

\section{Notes:}

1. The abbreviation $O A L D$ stands for Oxford Advanced Learner's Dictionary of Current English (2005), $7^{\text {th }}$ edition, Oxford: OUP.

2. The abbreviation FDF stands for The Free Dictionary of Farlex (Copyright 2003-2016) <www.thefreedictionary.com>.

\section{References:}

1. Berman, H.J. and Greiner, W.R. (1980) The Nature and Functions of Law. Mineola, N.Y.: Foundation Press.

2. Bhatia, K.L. (2010) Textbook on Legal Language and Legal Writing. New Delhi: Universal Law Publishing.

3. Farghal, M. \& Shunnaq, A.T (1999) Translation with Reference to English and Arabic: a practical guide. Irbid, Jordan: dar Al-Hilal for Translation.

4. Galperin, I.R. (1981) Stylistics. M.: visshaja shkola.

5. Gibbons, J. (2003) Forensic Linguistics: An Introduction to Language in the Justice System. Malden MA, Oxford: Blackwell.

6. Groot, de G. R. (1998) Language and Law. // Netherlands Reports to the Fifteenth International Congress of Comparative Law. / Ed. by E. H. Hondius. Bristol.

7. Hakobyan, A. (2009) Pashtonakan khosqn ibrev votchakarutsvatsqayin hatkanishneri uruyn hamaktsutyun (amerikyan sahmanadrutyan lezvakan nyuti himan vra). / teknatsuakan atenakhosutyan seghmagir. Yerevan: YPH. 
8. Kurzon, D. (1989) Language of the Law and Legal Language // Special Language: From Humans Thinking to Thinking Machines. / Ed by C. Lauren and N. Marianne. Clevedon/Philadelphia: Multilingual Matters, pp. 283-290.

9. Kurzon, D. (1997) Legal Language: Varieties, Genres, Registers, Discourses // International Journal of Applied Linguistics. Vol. 7, N2, pp. 119-139.

10. Mellinkoff, D. (1963) The Language of the Law. Little, Brown.Little, Brown.

11. Tiersma. P. (1999) Legal Language. Chicago: University of Chicago Press.

12. Trosborg, A. (1995) Introduction. Special Issue on "Laying down the LawDiscourse Analysis of Legal Institutions". // Journal of Pragmatics. Vol. 23, Issue 1, Elsevier, pp. 111-116.

13. Kouyoumdjian, M. (1981) A Comprehensive Dictionary: English-Armenian. Beitut-Lebanon: D. Doniguian \& Fils.

14. Sahakyan, L. (2012) Pokhaberakan teghasharji himnakhndiry terminasteghtsman (angleren iravabanakan terminneri nyuti himan vra). I teknatsuakan atenakhosutyan seghmagir. Yerevan: YPH.

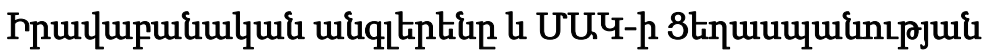

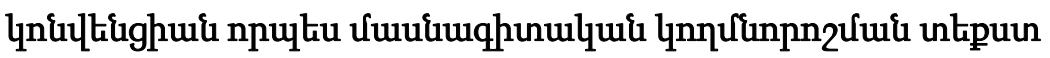

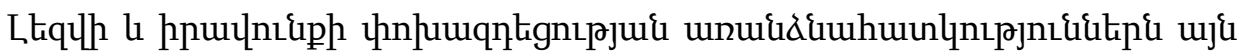

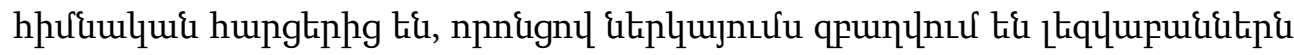

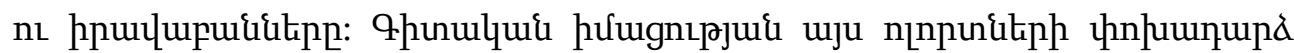

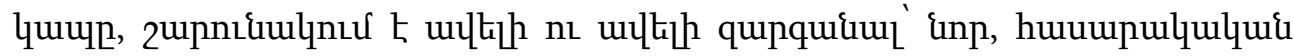

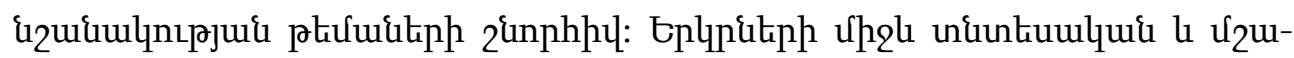

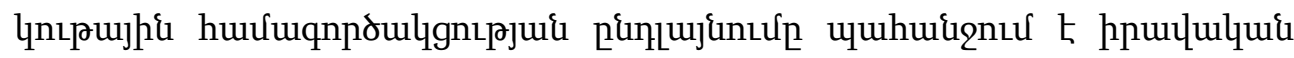

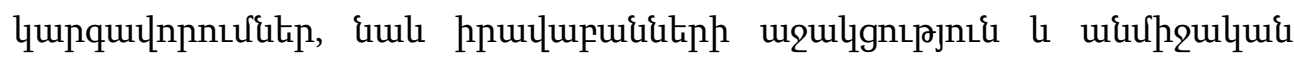

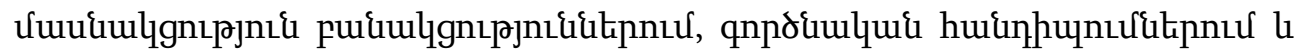

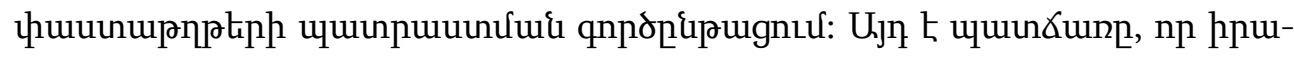

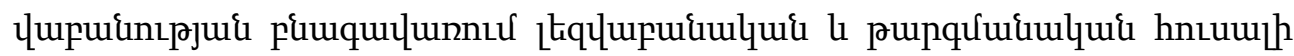

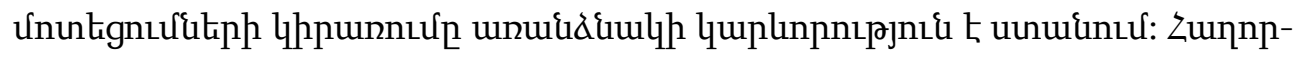

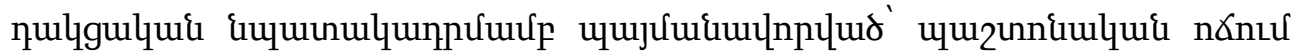

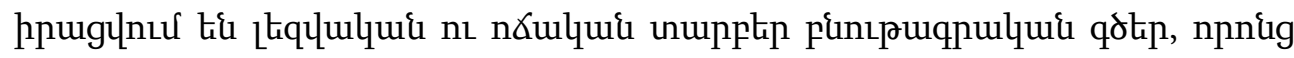

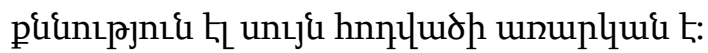

